\title{
A importância da brinquedoteca hospitalar e da Terapia Ocupacional sob a óptica da equipe de enfermagem de um hospital público do Distrito Federal
}

\author{
Caroline Jonas Rezaghi Ricomini Nunes ${ }^{a}$, Hellen Delchova Rabelo, \\ Denise Pinheiro Falcáoc, Marilucia Rocha de Almeida Picanço ${ }^{d}$ \\ ${ }^{a}$ Terapeuta ocupacional, Governo do Distrito Federal, Mestranda em Ciências Médicas, \\ Universidade de Brasília - UnB, Brasília, DF, Brasil \\ bEstudante do curso de Terapia Ocupacional, Universidade de Brasília - UnB, Brasília, DF, Brasil \\ 'Professora colaboradora, Departamento de Patologia, Faculdade de Ciências Médicas, \\ Universidade de Brasília - UnB, Brasília, DF, Brasil \\ ${ }^{d}$ Professora Adjunta de Pediatria, Faculdade de Medicina, Universidade de Brasília - UnB, Brasília, DF, Brasil
}

\begin{abstract}
Resumo: Introdução: O cuidado à criança hospitalizada sob a perspectiva de atenção integral não deve ser limitado às intervenções medicamentosas ou simplesmente às técnicas de reabilitação. A criança necessita ser considerada em sua singularidade e ter à sua disposição recursos que sejam de seu domínio para expressar-se, vivenciar e superar a experiência do adoecimento e da hospitalização. Nesse sentido, o brincar durante o período de adoecimento e internação hospitalar representa um meio privilegiado de ela entrar em contato com o mundo à sua volta. Objetivo: Verificar a opinião da equipe de enfermagem sobre a importância de uma brinquedoteca hospitalar e o modo como percebem o terapeuta ocupacional nesse contexto. Método: Aplicação de um questionário a profissionais da equipe de enfermagem da unidade de pediatria do terceiro maior hospital do Distrito Federal. Resultados: Percebeu-se a importância atribuída à brinquedoteca por parte da equipe de enfermagem, o reconhecimento do valor do terapeuta ocupacional e o desconhecimento acerca do seu papel e da influência do brincar na rotina da enfermagem. Conclusão: É extremamente necessário que o lúdico, cada vez mais, ganhe espaço no âmbito hospitalar, para todos os sujeitos envolvidos no processo saúde doença em que a criança está.
\end{abstract}

Palavras-chaves: Hospitalização, Terapia Ocupacional, Jogos e Brinquedos, Criança, Equipe de Enfermagem.

\section{The importance of hospital playroom and Occupational Therapy from the perspective of the nursing team of a public hospital in the Federal District}

\begin{abstract}
Introduction: The care provided to hospitalized children under the comprehensive perspective should not be limited simply to drug interventions and rehabilitation techniques. Children must be considered in their own singularities and they should have all known resources available to express themselves, and overcome hospitalization and the illness experience. In this sense, the playing during the period of illness and hospitalization represents a preferred means to keep contact with the world around them. Objective: To ascertain the views of the nursing team about the importance of a playroom in the hospital and the role of the occupational therapist in this context. Methods: A questionnaire was applied to the professional nursing staff of the pediatric unit of the third largest hospital in the Federal District. Results: Results demonstrated that the professional nursing team considers the playroom important and recognizes the occupational therapist's value, but they are not aware of the occupational therapist's role and the influence of the playing in the nursing routine. Conclusion: It is extremely necessary that playful activities increasingly gain ground in hospital settings through all subjects involved in the health-disease process in which children are inserted.
\end{abstract}

Keywords: Hospitalization, Occupational Therapy, Play and Playthings, Child, Nursing Team.

Autor para correspondência: Caroline Jonas Rezaghi Ricomini Nunes, Governo do Distrito Federal, Secretaria de Estado de Saúde do Distrito Federal, Hospital Regional de Ceilândia, QNM 17, Área Especial 01, Ceilândia, CEP 72215-170, Brasília, DF, Brasil, e-mail: caroljonas@ bol.com.br Recebido em 16/12/2011; Revisão em 27/9/2012; Aceito em 3/11/2012. 


\section{Introdução}

De acordo com Raabe (1980 apud HADLER; PERGHER, 2011, p. 418), a inserção da criança no universo do brincar é uma etapa fundamental em seu desenvolvimento cognitivo, físico e na socialização. A brincadeira é a principal ocupação nessa fase da vida do indivíduo e refletirá nas demais ocupaçóes da vida adulta. Os mesmos autores também citam Lucariello (1995), que salientou que as atividades lúdicas criam oportunidades de vivenciarem-se novas experiências que são indispensáveis. Nesses momentos, a criança se impóe no mundo com suas impressôes e ao mesmo tempo vai se construindo como sujeito, interagindo com o outro e conhecendo novas possibilidades. É quando ela expressa sua singularidade e subjetividade.

O brincar pelo brincar, caracterizado pela liberdade e onde a criança tem papel de sujeito ativo, é considerado imprescindível pelos resultados que proporciona. Nessa ocasião ela se expressa e igualmente compreende o que é comunicado pelo mundo externo, sendo essa construçáo algo fundamental e que, por si só, já é benéfica (HANSEN et al., 2007). Verificou-se em 505 jovens adultos que aqueles que tiveram o maior repertório lúdico tinham condutas e hábitos mais saudáveis. Isso indica que quanto maior for a vivência com o brincar, maiores serão os benefícios, não só durante a infância, mas também na vida adulta (CASSIDY et al., 2010).

Em ambiente hospitalar deve-se também favorecer esse tipo de atividade, uma vez que a brincadeira é um instrumento de domínio e conhecimento da criança (MITRE; GOMES, 2004). Além disso, é importante que a criança não rompa com o processo de desenvolvimento físico, cognitivo e social e que não abdique do seu papel ocupacional. A atividade lúdica no ambiente hospitalar não deve ser considerada uma mera "distração" mas, sim, um prosseguimento do processo de desenvolvimento infantil, que não deve ser rompido, na medida do possível, mesmo com as adversidades (MOTTA; ENUMO, 2004; SANTOS; MARQUES; PFEIFER, 2006).

Para que a criança seja atendida na sua integralidade, quando acometida pela hospitalização, suas demandas sociais e emocionais também devem ser observadas e supridas o quanto possível, com o uso de estratégias pertinentes de comunicação e acolhimento. Sendo assim, a atividade lúdica no hospital se torna um componente importante dentro da perspectiva de integralidade da criança, com vistas também ao cumprimento da Política Nacional de Humanização (PNH) do Sistema Único de Saúde (BRASIL, 2011).
O terapeuta ocupacional (TO) possui função relevante no contexto pediátrico já que ele tem competências para atuar em cada etapa do desenvolvimento da criança. Características patológicas e seus reflexos nas atividades cotidianas sáo aspectos importantes com os quais o terapeuta ocupacional pode e deve atuar no intuito de estimular as potencialidades que a criança ainda possui, apesar das condiçóes impostas pela enfermidade. $\mathrm{O}$ terapeuta ocupacional consegue adaptar as atividades necessárias às situaçôes adversas, tais como limitação de mobilidade, de postura, comprometimentos emocionais e de socialização da criança, dentre outras (DOMINGUES; MARTINEZ, 2001). $\mathrm{O}$ que se percebe, entretanto, é que as atividades lúdicas muitas vezes são interpretadas, até mesmo pela equipe de pediatria, como algo dispensável, por não resultar em ganhos "palpáveis", por assim dizer, para essas crianças. Sendo assim, o objetivo do presente estudo foi verificar a opinião da equipe de enfermagem sobre a importância da brinquedoteca hospitalar e como ela percebe o papel do terapeuta ocupacional nesse contexto.

\section{Materiais e método}

A pesquisa foi realizada na enfermaria pediátrica de um Hospital do Sistema Único de Saúde no Distrito Federal, no período de setembro a outubro de 2011. A enfermaria pediátrica contava com 38 leitos em 2011. De janeiro a setembro do mesmo ano houve uma média de 60 internaçóes por mês. A equipe é composta por cinco enfermeiros, 16 técnicos de enfermagem, cinco pediatras e um terapeuta ocupacional. Psicólogos, fonoaudiólogos e fisioterapeutas atuam somente com pedido de parecer.

Em 2006 foi inaugurada na pediatria uma brinquedoteca, cumprindo assim a Lei 11.104, que dispóe sobre a obrigatoriedade desse serviço nas unidades de saúde que ofereçam atendimento pediátrico em regime de internação (BRASIL, 2005). Esse espaço lúdico é coordenado por uma terapeuta ocupacional e funciona durante a semana no período matutino, permanecendo fechada nos finais de semana e feriados. Nos anos de 2010 e de 2011 (até setembro) frequentaram a brinquedoteca, respectivamente, 513 e 357 crianças. Nos anos anteriores náo há relatos do quantitativo de crianças que utilizaram o espaço.

As crianças hospitalizadas, cuja faixa etária varia de 0 a 12 anos e 11 meses, ficam internadas por tempo indeterminado, que pode variar de dias até 
semanas. Com exceçáo das que se encontram em isolamento devido a diagnóstico clínico, qualquer criança de qualquer idade é convidada e incentivada a frequentar o local.

No espaço da brinquedoteca, as atividades acontecem tanto individualmente quanto em grupo, paralelamente ou não. Atividades como jogos, bingos, brinquedos "de médico", bolas, colagem, bonecas, jogos de montar, brinquedos pedagógicos com figuras, carrinhos, brinquedos de animais, piscina de bolinhas, quebra-cabeças, jogos da memória, livros infantis, brinquedos sensório-motores, entre outras, são utilizadas como recursos pelo terapeuta ocupacional, tanto para estimular o desenvolvimento infantil como para minimizar o impacto negativo da hospitalização.

Um dos principais objetivos da Terapia Ocupacional, nesse contexto, é dar prosseguimento ao desenvolvimento global da criança, no qual o brincar é imprescindível, prevenindo ou diminuindo o estresse gerado durante a hospitalização (GIARDINETTO et al., 2009).

$\mathrm{O}$ instrumento utilizado para coleta de dados deste estudo foi um questionário (elaborado pelos responsáveis pela pesquisa) que continha 13 perguntas fechadas e uma aberta. Essas perguntas eram relativas ao significado do brincar para esses profissionais; dificuldades e facilidades do espaço lúdico da unidade de pediatria; relacionamento entre a equipe e a criança hospitalizada; e quais as perspectivas que os profissionais tinham para as açôes voltadas para o brincar. As variáveis relativas à caracterização da equipe foram gênero, tempo de formado e grau de formação.

O questionário, impresso em duas folhas de papel A4, ficou à disposição da equipe no "posto de enfermagem", ou seja, no local onde esses profissionais evoluem prontuários, realizam os procedimentos clínicos, respondem às prescriçôes médicas, entre outras atividades. Ao término das respostas, tarefa realizada em horário de trabalho e em que náo se utilizava mais que 10 minutos. O profissional respondente entregava o questionário para o responsável pela pesquisa. Todos os enfermeiros e técnicos (21 profissionais) que atuavam na unidade de pediatria foram convidados a participar desta pesquisa. Após o lançamento dos dados em uma planilha Excel, foi realizada estatística descritiva. Os resultados são apresentados de forma tabular.

\section{Resultados}

Ao todo, 19 dos 21 profissionais que compunham a equipe de enfermagem pediátrica responderam ao questionário, sendo $100 \%$ dos respondentes do sexo feminino. Catorze entrevistadas (74\%) têm formação como técnicas em enfermagem e cinco (26\%) são enfermeiras. Com relação a quanto tempo concluíram a sua formação, o grupo apresentou-se heterogêneo, com profissionais formados de três a até mais de 21 anos (Tabela 1).

Todos os participantes consideraram que brincar ajuda na recuperação da criança e $16 \%(\mathrm{n}=3)$ consideram que a atividade é imprescindível no âmbito hospitalar. $\mathrm{Na}$ análise dos profissionais acerca da funçáo da brinquedoteca, 26\% ( $\mathrm{n}=5)$ acreditam que as crianças se divertem, se distraem e que isso ajuda na recuperação. Quanto ao vínculo profissional-paciente, $95 \%(\mathrm{n}=18)$ considerou que a brinquedoteca auxilia no seu estabelecimento. Os entrevistados foram unânimes em considerar que o terapeuta ocupacional é imprescindível na brinquedoteca, porém $26 \%(\mathrm{n}=5)$ relataram não saber o papel desempenhado por esse profissional (Tabela 2).

Verificou-se que $15,8 \%(\mathrm{n}=3)$ dos entrevistados nunca utilizaram a brinquedoteca, $84,2 \%(\mathrm{n}=16)$ dos entrevistados utilizam a briquedoteca de 3 a 5 vezes por semana e essa mesma porcentagem acredita que o tempo disponibilizado é adequado; $42 \%(\mathrm{n}=8)$ afirmam que o brincar não atrapalha na rotina da enfermagem e igual porcentagem (42\%) acha que as atividades na brinquedoteca atrapalham a atuação da enfermagem, mas que não tem problema isso acontecer; $16 \%(\mathrm{n}=3)$ acham que atrapalha e isso os incomoda, conforme a Tabela 3.

Tabela 1. Caracterização da equipe.

\begin{tabular}{lcc}
\hline \multicolumn{1}{c}{ Gênero } & Quantidade & $\begin{array}{c}\text { Quantidade } \\
(\mathbf{\%})\end{array}$ \\
\hline Feminino & 19 & $100 \%$ \\
Masculino & 0 & $0 \%$ \\
\hline \multicolumn{1}{c}{ Tempo de } & Quantidade & $\begin{array}{c}\text { Quantidade } \\
\text { formação }\end{array}$ \\
\hline De 3 a 5 anos & 1 & $5,3 \%$ \\
De 6 a 10 anos & 2 & $10,5 \%$ \\
De 11 a 15 anos & 6 & $31,6 \%$ \\
De 16 a 20 anos & 1 & $5,3 \%$ \\
Acima de 21 anos & 6 & $31,6 \%$ \\
Não informou & 3 & $15,7 \%$ \\
\hline \multicolumn{1}{c}{ Formação } & Quantidade & $\begin{array}{c}\text { Quantidade } \\
(\%)\end{array}$ \\
\hline Técnico de enfermagem & 14 & $73,7 \%$ \\
Enfermagem & 5 & $26,3 \%$ \\
\hline
\end{tabular}


Tabela 2. Opinião da equipe acerca do brincar e da brinquedoteca.

\begin{tabular}{lcc}
\hline \multicolumn{1}{c}{ A importância do brincar no âmbito hospitalar é imprescindível? } & Número de pessoas & Número (\%) \\
\hline $\begin{array}{l}\text { É imprescindível } \\
\text { É importante no âmbito hospitalar }\end{array}$ & 3 & $16 \%$ \\
\hline \multicolumn{1}{c}{ O brincar ajuda na recuperação da criança? } & Número de pessoas & Número (\%) \\
\hline \multicolumn{1}{c}{$\begin{array}{c}\text { Análise dos profissionais acerca da função da } \\
\text { brinquedoteca na recuperação da criança }\end{array}$} & 19 & $100 \%$ \\
\hline Sim & Número de pessoas & Número (\%) \\
\hline $\begin{array}{l}\text { O brincar é muito importante para o desenvolvimento infantil, } \\
\text { portanto a brinquedoteca é fundamental }\end{array}$ & 11 & $58 \%$ \\
As crianças se divertem, se distraem, e isso acaba ajudando & & $26 \%$ \\
Sem opinião formada sobre isso & 5 & $11 \%$ \\
Não tem influência significativa & 2 & $5 \%$ \\
\hline \multicolumn{1}{c}{ O brincar auxilia no vínculo profissional-paciente? } & Número de pessoas & Número (\%) \\
\hline O brincar auxilia no vínculo & 18 & $5 \%$ \\
O brincar não auxilia no vínculo & 1 & $5 \%$ \\
\hline \multicolumn{1}{c}{ O terapeuta ocupacional é imprescindível na brinquedoteca? } & Número de pessoas & Número (\%) \\
\hline Sim & 19 & $100 \%$ \\
Conhecimento sobre o papel desempenhado pelo terapeuta & Número de pessoas & Número (\%) \\
ocupacional & & $74 \%$ \\
Sabe & 14 & $26 \%$ \\
Não sabe & 5 & \\
\hline
\end{tabular}

Tabela 3. A equipe de enfermagem e o uso da brinquedoteca.

\begin{tabular}{lcc}
\hline \multicolumn{1}{c}{ Periodicidade de uso da brinquedoteca } & Número de pessoas & Número (\%) \\
\hline Nunca utiliza & 3 & $15,8 \%$ \\
Utiliza de 3 a 5 vezes na semana & 16 & $84,2 \%$ \\
\hline Quanto ao tempo disponibilizado para o uso da brinquedoteca & Número de pessoas & Número (\%) \\
\hline Acha o tempo adequado & 16 & $84,2 \%$ \\
Acha pouco o tempo disponibilizado & 3 & $15,8 \%$ \\
\hline \multicolumn{1}{c}{ A influência da brinquedoteca na rotina da enfermagem } & Número de pessoas & Número (\%) \\
\hline Não atrapalha & 8 & $42 \%$ \\
Atrapalha, mas não tem problema isso acontecer & 8 & $42 \%$ \\
Atrapalha e isso incomoda & 3 & $6 \%$ \\
\hline
\end{tabular}

\section{Discussão}

A importância do brincar na recuperação da criança enferma pôde ser verificada com os resultados desta pesquisa. Santos, Marques e Pfeifer (2006, p. 95) citam Knox (2002), afirmando que os efeitos da hospitalização são minimizados quando a criança retoma sua principal ocupação, que é o brincar, pois essa é uma das maneiras com que ela compreende o mundo. Desse modo, quando esse espaço é reconhecido pela equipe, as açóes voltadas para o brincar se fortalecem, resgatando as possibilidades lúdicas que ficam comprometidas no período da hospitalização.

Todavia, notou-se que alguns profissionais ainda consideram que as atividades realizadas na brinquedoteca dificultam a rotina de enfermagem.
Dentre as participantes, técnicas de enfermagem acrescentaram espontaneamente as seguintes observaçóes:

Deve mudar o horário, pois é sempre na hora da medicação e isso atrapalha muito nosso serviço.

Devem ser observado os acessos venosos para não obstruir enquanto estiverem brincando [...] levá-los fora dos horários de medicaçôes.

Essas observaçóes podem ser reflexo da falha na comunicação entre os terapeutas e outros integrantes da equipe quanto à rotina hospitalar. Tais dificuldades podem ser resolvidas adotando-se certos procedimentos. Um deles, para mudar as ideias expressadas nesses relatos, seriam reuniōes periódicas, com o objetivo de sensibilizar todos os profissionais 
envolvidos no processo de internação, buscando a valorização do brincar como ação em saúde.

A frequência de uso da brinquedoteca (de 3 a 5 vezes por semana) apresentada pela maioria dos entrevistados (84\%) demonstra que esses profissionais vêm incorporando à sua prática o valor que o brincar tem para a criança. Morais (2009) menciona Lira (2002) quando explicita que ao lidar com a criança hospitalizada, no exercício de suas funçóes, o enfermeiro deve oferecer um cuidado diferenciado, de modo a suprir as necessidades dela conforme sua demanda e sua idade, levando em conta sua fase de desenvolvimento, pois isso influência diretamente na sua resposta frente à hospitalizaçáo. Tendo isso em vista, a apropriação da brinquedoteca também pela equipe de enfermagem, como espaço de cuidado e acolhimento, se faz elemento fundamental para que a criança seja integralmente assistida em sua recuperação.

Sendo assim, percebe-se que a brinquedoteca possui seu valor e que a visão acerca da importância do brincar está mudando, justamente por ser nítido o benefício trazido à criança hospitalizada. Isto ficou explícito nas seguintes observações espontâneas:

[...] sugiro que ela [a brinquedoteca] funcione todas as tardes, porque pela manhã atrapalha muito a rotina.

[...] a brinquedoteca deveria funcionar todos os dias em horários matutinos e vespertinos [...]. [...] a diferença no dia em que brincam é incrivel. Eu procuro brincar, distrair, divertir, isso funciona bem, gosto muito. É algo que funciona muito na recuperação das crianças.

De acordo com Mitre e Gomes (2004), o brincar deve ser compreendido como uma ação de saúde, pois facilita as dinâmicas das interaçôes e minimiza os impactos negativos da hospitalização, entre outros benefícios. Entretanto, na pesquisa realizada, um único profissional mencionou que o brincar pode ser uma ação em saúde, porém não conseguiu elucidar de maneira concreta o motivo:

[...] acho que pode ser uma ação em saúde porque faz bem.

Kishimoto (1998, p. 59) afirma que

[...] embora as brinquedotecas em hospitais não ocupem ainda um papel significativo no Brasil, elas são de extrema importância para a recuperação da criança internada.

Convém destacar que, mesmo com o reconhecimento da importância da brinquedoteca no contexto da criança hospitalizada, alguns profissionais continuam a não compreender e a não valorizar esse espaço. No Brasil, a brinquedoteca hospitalar existe há pouco tempo, isso é, desde março de 2005, com a Lei Federal n. 11.104 (BRASIL, 2005) a sua existência se tornou obrigatória nas unidades de saúde. A opiniāo de alguns dos entrevistados (42\%), afirmando que o brincar atrapalha a rotina da enfermagem, também contribui para essa "desvalorização", possivelmente associada a fatores históricos e culturais, pois é necessário tempo para que essas açóes se estabeleçam plenamente (SILVA; MATOS, 2009, p. 8).

Em contraponto, o reconhecimento da importância do brincar e do espaço da brinquedoteca por $58 \%$ dos entrevistados nos deixa otimistas de que, aos poucos, as potencialidades da brinquedoteca como local de socialização, de convivência, de autonomia e expressão, de acolhimento, melhora da qualidade de vida e melhora do humor, entre outras, serão reconhecidas pelos profissionais da área da saúde.

Quando 95\% dos entrevistados dizem que o brincar auxilia no vínculo profissional-paciente, remetem ao conceito de ludicidade. De acordo com Luckesi (2005, p. 2), o lúdico deve ser pleno e funcional e não deve ser confundido com mera repetiçáo, aparentemente sem objetivo. Dessa forma, por envolver o sujeito de modo integral, os vínculos se reafirmam através do brincar, pois ambos estão ali juntos integrando ação, pensamento e sentimento. Nesse sentido, essa atividade lúdica abre caminhos para a humanização, o acolhimento, o diálogo e o fortalecimento dos sujeitos envolvidos.

De acordo com Knox (2002 apud SANTOS; MARQUES; PFEIFER, 2006, p. 98), o terapeuta ocupacional tem uma atuação específica junto à criança hospitalizada, já que esse evento pode prejudicar o seu desempenho ocupacional. Esse profissional é capacitado para analisar e avaliar o brincar, planejar intervençóes pertinentes às competências cognitivas, motoras e sociais da criança. No presente estudo, todos os participantes concordaram que o papel do terapeuta ocupacional é fundamental, porém verificou-se que alguns ainda desconhecem o campo de atuaçáo desse profissional. Isso mostrou que ainda existe uma lacuna na consolidação da Terapia Ocupacional no âmbito da pediatria. A brinquedoteca é um espaço importante, que deve ser explorado conjuntamente pela equipe, e é importante que cada profissional esteja a par das funçôes de cada integrante da equipe. Levando-se em conta que os entrevistados reconhecem o papel do terapeuta ocupacional, seria importante também tomar conhecimento acerca das especificidades dessa profissão. 


\section{Conclusão}

O brincar e a brinquedoteca possuem papel de grande relevância na hospitalização infantil, permitindo a continuação do desenvolvimento dessa criança, bem como a melhora do seu comportamento, a redução de seu estresse e a melhoria nas relaçóes que ela manterá durante o tempo de hospitalização. Partindo disso, é extremamente necessário que o lúdico, cada vez mais, seja valorizado no âmbito hospitalar por todos os sujeitos envolvidos no processo saúde-doença em que essa criança está inserida. Contudo, para que isso se torne realidade, faz-se necessário uma maior divulgação sobre as habilidades e competências do terapeuta ocupacional no meio acadêmico e hospitalar.

\section{Referências}

BRASIL. Lei 11.104/2005, de 21 de março de 2005. Dispóe sobre a obrigatoriedade de instalação de brinquedotecas nas unidades de saúde que ofertem regime de atendimento pediátrico em regime de internação. Diário Oficial da República Federativa do Brasil, Brasília, DF, 23 mar. 2005. Seção 1. Disponível em: <http://www.planalto. gov.br/ccivil_03/_Ato2004-2006/2005/Lei/L11104. htm>. Acesso em: 10 set. 2011.

BRASIL. Ministério da Saúde. Caderno Humaniza SUS, Atenção Hospitalar. Brasília: Ministério da Saúde, 2011. Disponível em: <http://bvsms.saude.gov.br/bvs/ publicacoes/cadernos_humanizasus_atencao_hospitalar. pdf>. Acesso em: 19 out. 2011.

CASSIDY, T. et al. Creative and active play in childhood is linked to good adult health. London: British Psychological Society, 2010. Disponível em: <http:// www.medicalnewstoday.com/releases/185472.php >. Acesso em: 11 nov. 2011.

DOMINGUES, A. C. G.; MARTINEZ, C. M. S. Hospitalização Infantil: Buscando identificar e caracterizar experiências de terapia ocupacional com crianças internadas. Cadernos de Terapia Ocupacional da UFSCar, São Carlos, v. 9, n. 1, p.16-29, 2001.

GIARDINETTO, A. R. D. S. B. et al. A importância da atuação da terapia ocupacional com a populaçáo infantil hospitalizada: A visão de profissionais da área da saúde.
Cadernos de Terapia Ocupacional da UFSCar, São Carlos, v. 17, n. 1, p. 53-62, 2009.

HADLER, A.; PERGHER, G. K. O uso da brincadeira na terapia cognitiva comportamental. In: WAINER, R. et al. Novas Temáticas em Terapia Cognitiva. São paulo: Sinopsys Editor e Sistemas Ltda., 2011. p. 415-428.

HANSEN, J. et al. O brincar e suas implicaçôes para o desenvolvimento infantil a partir da Psicologia Evolucionista. Revista Brasileira Crescimento Desenvolvimento Humano, Sáo Paulo, v. 17, n. 2, p. 133-143, 2007.

KISHIMOTO, T. M. Diferentes Tipos de Brinquedoteca. In: FRIEDMANN, A. (Org.). O Direito de Brincar: a brinquedoteca. São Paulo: Edições Sociais, 1998. p. 53-63. LUCKESI, C. C. Ludicidade e Atividade Lúdicas - Uma abordagem a partir da experiência interna. Salvador: Cipriano Carlos Luckesi, 2005. Disponível em: <http:// www.luckesi.com.br/artigoseducacaoludicidade.htm $>$. Acesso em: 11 set. 2012.

MITRE, R. M. D. A.; GOMES, R. A promoção do brincar no contexto da hospitalizaçấo infantil como ação de saúde. Ciência e Saúde Coletiva, Rio de Janeiro, v. 9, n. 1, p. 147-154, 2004.

MORAIS, G. S. D. N. O brincar na construção de um cuidado integral à criança hospitalizada. In: ENCONTRO NACIONAL DE BIOÉTICA E BIODIREITO, 2., 2009, João Pessoa. Anais... João Pessoa: Editora Universitária UFPB, 2009. Disponível em: <http://189.75.118.67/ CBCENF/sistemainscricoes/arquivosTrabalhos/I11128. E3.T2317.D3AP.pdf>. Acesso em: 11 set. 2012.

MOTTA, A. B.; ENUMO, S. R. F. Brincar no hospital: estratégia de enfrentamento da hospitalizaçáo infantil. Psicologia em Estudo, Maringá, v. 9, n. 1, p. 19-28, 2004. http://dx.doi.org/10.1590/S1413-73722004000100004

SANTOS, C. A.; MARQUES, E. M.; PFEIFER, L. I. A brinquedoteca sob a visão da terapia ocupacional: diferentes contextos. Cadernos de Terapia Ocupacional da UFSCar, São Carlos, v. 14, n. 2, p. 91-102, 2006.

SILVA, T. M. A. D.; MATOS, E. L. M. Brinquedoteca Hospitalar: Uma realidade de humanizaçáo para atender crianças hospitalizadas. In: CONGRESSO NACIONAL DE EDUCAÇÃO, 9.; ENCONTRO SUL BRASILEIRO DE PSICOPEDAGOGIA, 3., 2009, Curitiba. Anais... Curitiba: EDUCERE, 2009. p. 10602-10612. Disponível em: <http://www.pucpr.br/eventos/educere/educere2009/ anais/pdf/3276_1464.pdf $>$. Acesso em: 11 set. 2012.

\section{Contribuição dos Autores}

Caroline Jonas Rezaghi Ricomini Nunes: Responsável pela pesquisa, redigiu o texto. Hellen Delchova Rabelo: Participou da pesquisa, colaborou com a redação, organização dos dados e das referências. Denise Falcão e Marilucia Rocha de Almeida Picanço: Orientadoras da pesquisa. 